\title{
Retracted: On the Geoeffectiveness Structure of Solar Wind-Magnetosphere Coupling Functions during Intense Storms
}

\author{
ISRN Astronomy and Astrophysics \\ Received 18 December 2013; Accepted 18 December 2013; Published 23 January 2014 \\ Copyright (C) 2014 ISRN Astronomy and Astrophysics. This is an open access article distributed under the Creative Commons \\ Attribution License, which permits unrestricted use, distribution, and reproduction in any medium, provided the original work is \\ properly cited.
}

\begin{abstract}
The article titled "On the Geoeffectiveness Structure of Solar Wind-Magnetosphere Coupling Functions during Intense Storms" [1], published in ISRN Astronomy and Astrophysics, has been retracted as it is found to contain a substantial amount of material from the article by Yermolaev, Y. I., and M. Y. Yermolaev (2008), Comment on "Interplanetary origin of intense geomagnetic storms (Dst $<-100 \mathrm{nT}$ ) during solar cycle 23 " by W. D. Gonzalez et al. Geophys. Res. Lett., 35, L01101, doi:10.1029/2007GL030281.
\end{abstract}

\section{References}

[1] B. Olufemi Adebesin, S. Oluwole Ikubanni, and J. Stephen Kayode, "On the geoeffectiveness structure of solar windmagnetosphere coupling functions during intense storms," ISRN Astronomy and Astrophysics, vol. 2011, Article ID 961757, 13 pages, 2011. 